\title{
Inclusão, exclusão e cidadania como desafio para a política em regiões de modernidade periférica
}

Armin Mathis - Professor e pesquisador do Núcleo de Altos Estudos Amazônicos da Universidade Federal do Pará - NAEA/UFPA.

\section{Resumo}

No Brasil pode-se observar que no discurso político a exclusão social ganha cada vez mais destaque. A atuação política nesse campo é altamente destinada à criação de legitimidade para o próprio sistema social. Dentro do processo da geração de legitimidade o sistema político requer cada vez mais responsabilidades para si, não obstante, sem poder lograr sua efetiva implementação. Pode-se ilustrar esse fato através do confronto entre ampliação semântica do conceito de cidadania e a realidade empírica das violações dos direitos humanos no Estado do Pará com enfoque nas ações direcionadas à cidadania e às pessoas com deficiência. Portanto, a intervenção do poder público não foi capaz de conter o processo de exclusão múltipla oriundo da atuação 'cega' dos sistemas funcionais da sociedade moderna.

\begin{abstract}
Social exclusion is more and more emphasized in the political discourse in Brazil. Political action, in this field, is strongly aimed at creating legitimacy for the social system itself. Within this process of legitimacy creation, the political system claims more responsibility for itself, despite its failure in achieving an effective implementation. This fact is observed through the comparison between a semantic amplification of the concept of citizenship and the empiric reality of human rights violations in the State of Pará, mainly focusing on the actions towards citizenship and impaired people. The governmental intervention, however, has not been able to halt the multiple exclusion process that resulted from the 'blind' action of functional systems in modern society.
\end{abstract}

\section{Keywords}

Inclusion, Exclusion, citizenship and body. 


\section{INTRODUÇÃO}

Neste artigo, emprega-se a teoria dos sistemas para discutir o problema da inclusão e exclusão em regiões de modernidade periférica e relacioná-lo com um estudo de caso sobre os portadores de deficiência no Estado do Pará.

Com base na teoria dos sistemas sociais, interpreta-se qualquer contato social como um sistema. Em linhas gerais, distinguem-se três tipos de sistemas sociais: os sistemas de interação, os sistemas de organização e a sociedade - um sistema social mais amplo. A interação, primeiro tipo de sistema, caracteriza-se pelo fato de que os sistemas psíquicos presentes percebem-se como integrantes de um mesmo sistema. As organizações, segundo tipo de sistemas, condicionam a qualidade de sócio e, de acordo com as regras de qualidade de sócio, conseguem reproduzir modos de comportamento, independentemente dos motivos individuais dos seus membros. Por último, a sociedade é o sistema mais amplo, que inclui todos os outros sistemas sociais.

Desse modo, a operação básica de qualquer sistema social é a comunicação, que constitui um processo de tripla seleção. Ela começa com o alter, que seleciona uma informação dentro do seu ambiente (primeira seleção), escolhe um meio de comunicação que serve para transmitir a informação como mensagem (segunda seleção) e concluise com o ego, o destinatário da mensagem, que pode compreendê-la ou não (terceira seleção). Esse processo de comunicação é considerado um acontecimento de curta duração, que se realiza - e desaparece - no momento em que o ego compreende aquilo que o alter quer comunicar. Nessa interpretação do processo de comunicação, importa enfatizar o papel do destinatário. Somente o seu entendimento é decisivo para o sucesso ou não da comunicação, e esse sucesso não deve ser confundido com aceitação da comunicação. A aceitação ou a rejeição - concordar ou não - com uma comunicação já é um outro evento comunicativo.

A definição do processo comunicativo como tripla seleção permite ao sistema distinguir entre hetero-referência (seleção da informação feita fora dos limites do sistema) e auto-referência (seleção da informação feita dentro dos limites do sistema); nesse sentido, reproduz permanentemente a divisão sistema vs meio e garante assim a sua existência.

Sistemas sociais processam a sua comunicação baseada no sentido, e é esse sentido que os liga aos sistemas psíquicos, os quais, por sua vez, têm no processamento de pensamentos a sua operação básica. Esse mecanismo de acoplamento estrutural fornece ao sistema social o suporte material para a sua comunicação e ao sistema psíquico a possibilidade da sua socialização.

\section{Modernização periférica}

\subsection{Modernização como processo de diferenciação}


Essa introdução justifica-se para explicar a constituição da sociedade moderna como resultado de um duplo processo de diferenciação. Por um lado, a evolução leva a uma diferenciação, cada vez mais nítida, entre os diferentes tipos de sistemas sociais; por outro, essa evolução impulsiona uma diferenciação dentro dos diferentes tipos de sistemas sociais. Os dois processos constituem-se de forma ortogonal. O primeiro obedece a uma lógica vertical de segregação - imprimindo assim uma hierarquia entre os sistemas envolvidos. O segundo caracteriza-se por uma dinâmica de diferenciação horizontal, e a sociedade divide-se em sistemas funcionais. Esses subsistemas assumem funções específicas para toda a sociedade.

A operação básica de tais sistemas é a comunicação, e a diferenciação do sistema significa também diferenciação da comunicação. Os subsistemas funcionais tornam-se distintos por meio da elaboração de uma estrutura própria de comunicação. Essa diferenciação da comunicação é possibilitada por dois ganhos evolutivos: 1) a formação de códigos binários específicos que orientam a comunicação e a visão de mundo do sistema; 2.) a formação de meios de comunicação simbolicamente generalizados que asseguram a continuidade da comunicação no sistema.

O código representa uma visão total do mundo, que passa a ser observado pelo sistema funcional, somente por meio da diferença específica estabelecida pelo código. Assim sendo, a visão do mundo de um sistema funcional é aquela que lhe permite o seu código. E, como cada sistema funcional tem um código específico, cada sistema funcional também tem sua versão particular de mundo, conseguindo no máximo observar que existem ao redor visões diferentes do mundo.

A diferenciação funcional da sociedade, que se iniciou no século XVI e se consolidou no início do século XX, é a ultima de quatro formas de diferenciação que podem ser observadas historicamente. A primeira foi a diferenciação segmentária, onde os subsistemas da sociedade são iguais. Podemos lembrar certos grupos tribais que vivem sem muito contato entre si. A segunda forma de diferenciação surge com a transformação de um desses segmentos, normalmente designado como centro, em algo diferente dos outros, que formam a periferia. Resulta desse processo a distinção entre centro (único) e periferia (várias formações iguais entre si, mas distintas do centro). A terceira forma de diferenciação, chamada estratificada, foi dominante na Idade Média. Nela a sociedade é dividida em camadas, que constituem uma hierarquia.

\footnotetext{
É possível citar alguns sistemas funcionais com os seus códigos binários e meios de comunicação simbolicamente generalizados: a política usa o código binário poder/não-poder ou governar/não-governar, e o poder é o seu meio de comunicação simbolicamente generalizado; a ciência emprega o código binário verdadeiro/falso, e seu meio de comunicação simbolicamente generalizado é a verdade; a economia vê o mundo por meio do código binário pagar/não-pagar ou propriedade/não-propriedade, e o dinheiro é o seu meio de comunicação.

${ }^{2}$ Luhmann (1975a, p. 177) denomina o código e o meio de comunicação simbolicamente generalizado 'autocatalisadores', para deixar claro que eles surgem no processo comunicativo do sistema e depois contribuem para a evolução do processo comunicativo.
} 
Em geral, o processo de modernização acontece com a mudança de uma diferenciação estratificada em uma diferenciação funcional. Na diferenciação estratificada, a sua camada de origem define o destino de um indivíduo em um duplo sentido. De um lado, a origem de nascimento marca a posição dentro da sociedade, e não existe - a não ser nos contos de fadas - a transição de uma camada social para outra camada. Desse modo não há mobilidade social. Na comunicação esse fato expressa-se em uma valorização da dimensão social em detrimento da dimensão objetiva. Importante é quem diz algo, e não o que foi dito. Portanto, a camada de origem marca a visão da sociedade, que é vista com base na diferenciação principal acima/embaixo. De outro lado, o conhecimento da própria camada social em conjunto com o conhecimento do 'seu lugar' na sociedade é reforçado pela religião. Dessa maneira, a religião apresenta-se como intérprete exclusivo do mundo e oferece ao indivíduo segurança, no sentido de criar a capacidade de entender a sociedade em que vive.

O ganho evolutivo da sociedade moderna em relação à diferenciação estratificada da sociedade pré-moderna é o aumento expressivo da capacidade de processar complexidade. No entanto, há custos para esse ganho. A diferenciação funcional por meio da formação de subsistemas é um processo de diferenciação horizontal, com conseqüências graves para a sociedade, que perde o seu centro e assim o lugar que pode representar a sua identidade. As visões diferentes dos sistemas funcionais não podem ser agregadas para formar um todo. Os sistemas funcionais são iguais na sua diferença. A unidade da sociedade constitui-se exclusivamente no nível do sistema funcional como unidade da autoreferência e da hetero-referência da sua observação . A falta de um centro ou de um topo faz com que a diferenciação funcional demande novas soluções para garantir a integração da sociedade e requer mecanismos de reflexão sobre os riscos que a eficiência dos sistemas funcionais representa para a sociedade como um todo.

\subsection{Modernização na periferia}

A sociedade como um sistema social mais amplo, constituída pela totalidade das comunicações, é necessariamente única e assim global (Weltgesellschaft ). No entanto, isso se refere somente ao seu modus operandi. A sua forma concreta - no âmbito local, regional ou nacional - é diversificada e aparece como o resultado da forma como se implementam os sistemas funcionais dentro da estrutura social existente ${ }^{5}$. Historicamente podemos notar que poucos sistemas sociais

\footnotetext{
3 A unidade da sociedade é possível somente como policontextualidade dos mundos específicos dos sistemas funcionais, isto é, como o conjunto de horizontes que os sistemas funcionais erguem sobre a sociedade.

${ }^{4}$ Luhmann introduz o conceito de Weltgesellschaft na sua teoria em 1975. No entanto, ele não se referiu às tendências que depois foram subsumidas sobre o conceito de globalização (LUHMANN, 1975b).

5 O processo de formação de sistemas funcionais não é um processo com uma mesma temporalidade. No sistema da economia e da ciência moderna, esse processo ocorreu com muito mais rapidez.
} 
foram capazes de 'sobreviver' às perturbaçōes que o avanço da diferenciação funcional representa no seu meio .

A partir da Segunda Guerra Mundial, a modernização deixou de ser o resultado de um processo evolutivo e tornou-se objeto da atuação do Estado nacional, que assume para si a tarefa de condução dos processos de transformação social . A modernização implanta-se com características regionais e conforme se apresenta o Estado nacional na concorrência das nações. O Estado nacional coloca-se, portanto, entre o nível regional e o nível global. No entanto, ele é obrigado a realizar essa ação sem muita liberdade de ação, porque a diferenciação funcional da sociedade global define as estruturas que o Estado nacional pode impor à região como condição para o seu ingresso na modernidade. A modernização, no âmbito regional, processa-se dentro das estruturas da sociedade funcionalmente diferenciada. Vale ressaltar que, na sociedade global, não há uma instância de coordenação, nem a necessidade de uma evolução para um equilíbrio. Tal fato traz divẹssas conseqüências para a forma de modernização no âmbito regional .

A formação dos sistemas funcionais decorre de um processo evolutivo; por isso não há como planejar ou repetir no âmbito regional o que aconteceu no âmbito global durante o processo da formação da sociedade moderna. Ainda, no que diz respeito à evolução no âmbito regional, observa-se que a modificação da estrutura da sociedade sempre é uma modificação de estruturas existentes, por meio da seleção de alternativas que surgem dentro dessas estruturas antigas. O novo sempre carrega consigo o velho. Nada garante que a improvável formação de subsistemas com funções exclusivas aconteça. É muito mais provável que se formem sistemas funcionais corruptos, no sentido de não conseguirem para si a exclusividade de uma função dentro da sociedade regional.

\section{Inclusão vs exclusão ${ }^{10}$}

O avanço do modus operandi dos sistemas funcionais e a perturbação das estruturas sociais regionais são processos no nível da sociedade. Como operações comunicativas, as estruturas sociais

\footnotetext{
${ }^{6}$ Marcelo Neves (1992) iniciou estudos pioneiros sobre esse assunto, tomando como caso empírico o Brasil e a formação do sistema de direito. Ainda não existem estudos no âmbito regional que analisem mais profundamente os processos de transformação com base nas condições postas pelos sistemas funcionais.

7 Pode-se dizer que esse fato por sua vez é resultado do processo de diferenciação funcional: a transformação de ex-colônias em Estados nacionais, isto é, a formação de novos segmentos nacionais dentro do sistema político.

8 Sobre política de desenvolvimento e teoria de sistemas, ver Mathis (1999).

${ }^{9}$ Luhmann (1995) chama a atenção, por exemplo, para o fato de que as redes sociais em áreas periféricas tradicionalmente ligadas a estruturas clientelistas modernizam-se por meio da substituição do patrimônio privado pelas organizações, que passam a ser fontes de recursos para sustentar a rede.

${ }^{10}$ Além dos trabalhos de Luhmann, existem vários estudos na teoria dos sistemas que abordam a problemática da inclusão vs exclusão. A revista Soziale Systeme dedicou em 2002 um volume inteiro (v. 8) ao tema.
} 
precisam do suporte material dos sistemas psíquicos. Sem esse suporte, não há como garantir a continuidade do processo comunicativo dentro dos sistemas funcionais. Ao mesmo tempo, os sistemas funcionais colocam-se para os sistemas psíquicos como o único locus de sua sociabilidade $^{11}$. O fato de recorrer aos sistemas funcionais como veículos de inclusão social faz com que a sociedade moderna reconstrua a diferença inclusão vs exclusão dentro da sociedade.

Para que isso aconteça, a sociedade precisa ter como pressuposto a possibilidade da participação de todos os indivíduos em cada sistema funcional. Aliás, a formação da individualidade é baseada nesse mecanismo . A inclusão estabelece-se por meio da participação na possibilidade de comunicação que cada sistema funcional oferece ${ }^{13}$. Em outras palavras, a sociedade moderna coloca a inclusão meramente como problema individual. Esse mecanismo nutre a ilusão de inclusão sem exclusão.

No entanto, isso é somente ilusão, porque, na realidade, formamse esferas de exclusão , uma exclusão que muitas vezes não é somente exclusão de um sistema funcional. A exclusão de um sistema funcional normalmente leva à exclusão de outros sistemas, e essa exclusão social apresenta-se quantitativa e qualitativamente diferente daquela de outras formações da sociedade.

A exclusão pode ser interpretada também como perda de endereço social $^{15}$. O indivíduo não é mais notado como pessoa, ele está sem papel social e, em geral, sem os laços sociais das sociedades estratificadas, que foram desestruturadas logo no início do processo da modernização. Privado da sua sociabilidade, ele é somente corpo, e o corpo e suas necessidades básicas determinam o seu comportamento na sociedade, que se reduz à mera reprodução desse corpo, à sobrevivência (LUHMANN, 1996, p. 189). Reduzido ao corpo, a única maneira de o indivíduo inserir-se na sociedade, de incluir-se nos sistemas funcionais,

\footnotetext{
${ }^{11}$ Inclusão vs exclusão é um problema que qualquer formação social enfrenta. No entanto, as formas de enfrentar esse problema são distintas. Em sociedades segmentárias, exclusão sempre foi exclusão total do indivíduo por meio da liberação para a morte ou o desterro. $\mathrm{Na}$ sociedade estratificada, a inclusão é tarefa da camada social, por meio da família ou da categoria de trabalho. Novidade é a existência de formas organizadas no lado da exclusão. Formam-se mecanismos de integração no lado da exclusão (por exemplo, obras de caridade, mosteiros, a Marinha, as províncias, a pirataria nos navios).

${ }^{12}$ Cada indivíduo agora é responsável por sua carreira, como resultado da sua formação própria. E isso em um sentido duplo: formação dentro do sistema educativo e formação conforme um plano e desejos individuais. A camada social de origem não determina mais o lugar na sociedade, nem a carreira alcançada diz algo sobre a origem da pessoa (claro que ainda tem influência sobre o acesso à educação, por exemplo). O indivíduo agora tem de mostrar para a sociedade quem ele é. Para mais exemplos, ver Fuchs (1997a).

${ }^{13}$ Creio que isso, em parte, é uma outra forma de explicar aquilo que Jessé Souza (2000) denomina "modernização seletiva".

${ }^{14}$ É interessante observar os mecanismos que a sociedade moderna criou para nutrir essa ilusão. Podemos citar o mecanismo de tornar os excluídos ocultos, seja por meio de separação geográfica (favelas), seja por meio de internação ou institucionalização. Pode-se também lembrar o papel excepcional do tempo como meio de transformar exclusão em inclusão por meio de políticas de desenvolvimento.

${ }^{15}$ Sobre a categoria 'endereço social', ver Fuchs (1997b).
} 
é fazer uso desse corpo, seja na prostituição, seja como modelo, seja como vendedor de seus órgãos ou das suas crianças, seja como jogador de futebol.

Analisar a diferença inclusão vs exclusão como problema da participação individual em sistemas funcionais significa atribuir a um lado dessa distinção (inclusão) uma conotação positiva e, a partir dessa decisão, detectar na vida social momentos de exclusão (= inclusão não realizada) que precisam ser colocados no outro lado da distinção (= transformar exclusão em inclusão). Mas será que o problema se restringe a essa explicação? Será que não há um problema atrás do problema?

Vamos duplicar a diferença e colocar uma segunda distinção (inclusão vs exclusão) sobre a primeira (inclusão vs exclusão) ${ }^{16}$. Em outras palavras, definimos a distinção como contingente (algo que é como é, mas não é necessariamente assim como é) e observamos a existência (inclusão) ou não (exclusão) da distinção inclusão vs exclusão. Construímos assim uma metadiferença acima dos códigos dos sistemas funcionais (LUHMANN, 1997a, p. 632). Isso abre o olhar para as esferas nas quais o mecanismo de inclusão vs exclusão por meio do sistema funcional se realiza e onde há equivalências funcionais para esse mecanismo. Essa falta de exclusividade do processo de inclusão por meio da inclusão em um sistema funcional é um indicador das manchas da modernidade periférica, isto é, dos contextos sociais em que a sociedade moderna não se implementou em sua plenitude de funcionamento.

Na prática isso se traduz, por exemplo, na possibilidade de tomar uma decisão sobre o uso ou não do sistema de direito para decidir um litígio, ou na possibilidade de prover o acesso a bens e serviços sem dinheiro. Claro que essa decisão de não entrar em um sistema funcional requer recursos para impor a sua vontade sem recorrer à autoridade do sistema funcional, seja porque essa vontade faz parte da organização que mantém o monopólio legítimo de poder (caso da polícia e das Forças Armadas) ${ }_{17}$ seja porque não há presença ou vontade política de atuação do Estado.

Fica evidente que, em regiões de modernidade periférica, a inclusão social não constitui somente um problema individual no que se refere à condição de ter ou não acesso ao sistema funcional. Conseguir o acesso em nada adianta sem a garantia da exclusividade funcional dos sistemas . Isso remete novamente ao Estado como condutor de processo de mudança social.

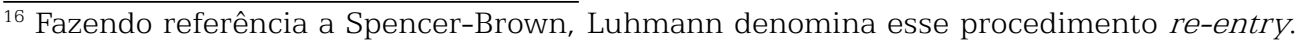

${ }^{17}$ Vontade política no sentido tanto de colocar a lei em prática, como de não impedir o uso privado de força.

${ }^{18}$ Stichweh (1997) chama a atenção para os fatores de exclusão que não podem ser atribuídos ao processo da diferenciação funcional. Ele cita como exemplos a segregação étnica e a migração.
} 


\section{O Estado na modernidade periférica: inclusão por via da cidadania ou cidadania por via da inclusão?}

É possível recontar a história do Estado moderno como uma absorção parcial pelo Estado da tarefa individual de inclusão ${ }^{19}$. O Estado moderno legitima-se por meio da definição e do reconhecimento de direitos humanos universais fixos ${ }^{20}$ e da sua submissão ao direito positivo, que é passível de mudança ${ }^{21}$. Alguns súditos transformam-se em cidadãos do Estado nacional ${ }^{22}$. A universalização do direito de cidadania para todos, expressa no sufrágio universal, tornou-se um dos pontos principais da pauta política no início da história dos Estados nacionais. A fundamentação nos direitos humanos, pelo menos em parte, coloca à disposição do Estado moderno um instrumento capaz de assegurar a integração social, sem exigir um consenso entre os cidadãos $^{23}$. Essa capacidade de gerar integração social deu aos sistemas funcionais a liberdade inicial de exercer a sua autopoiese e de aprofundar as diferenciações entre a população.

No entanto, o fim do Estado liberal mostrou que o papel integrativo dos direitos humanos não sustenta uma sociedade cada vez mais caracterizada por diferenças internas. O Estado assume um papel mais ativo na materialização dos direitos humanos e assume a legitimidade de restringir as externalidades negativas não aceitáveis dos sistemas funcionais $^{24}$. Registra-se a passagem do Estado, pelo menos nas partes do mundo onde a diferenciação funcional instalou-se na sua plenitude, para um Estado de bem-estar social. Desse modo, o Estado intervém cada vez que a lógica da economia de mercado excede o grau normal de destruição (destruição de empresas não competitivas) e das externalidades negativas normais (danos ambientais, desemprego), de tal maneira que não foi possível contê-la com a criação de novas

\footnotetext{
${ }^{19}$ Halfmann (2002) distingue a inclusão no sistema político da tarefa do Estado nacional de garantir a inclusão dos cidadãos nos sistemas funcionais. Em nossa abordagem, vamos a seguir focar a segunda tarefa: a da criação de condições para inclusão (Inklusionsvermittlung). Tratamos o problema do Estado na periferia moderna em outro contexto (MATHIS, 2001).

${ }^{20}$ Talvez seja mais adequado chamar os direitos humanos de unidirecionais. Nesse sentido, há uma tendência histórica para ampliar o seu enfoque, e dificilmente a retirada de um direito já concedido é socialmente aceita. A menos que se invoque uma entidade maior do que o próprio Estado nacional - como a ameaça do terrorismo internacional.

${ }^{21} \mathrm{~A}$ arbitrariedade de decisão do príncipe é substituída pela arbitrariedade dos direitos humanos consagrados em Constituições políticas (LUHMANN, 1997, p. 967). Além disso, vale lembrar que os direitos humanos obedecem ao principio da universalidade, enquanto a cidadania vincula os direitos à condição de ser membro de um Estado como organização territorial.

${ }^{22}$ Parece que a função do Estado nacional de tornar visível uma unidade coletiva é algo muito atual em tempos de globalização (NASSEHI, 2002).

${ }^{23}$ Direitos humanos em um ambiente de consenso completo serão desnecessários. Ver a discussão interessante de Neves (2007), que lembra também que os direitos humanos têm uma função importante na redução de complexidade.

${ }^{24} \mathrm{~A}$ ameaça da integridade física dos cidadãos que devido a características individuais (doença, acidente, idade, deficiência) não foram capazes de assegurar a sua reprodução através da inclusão no sistema econômico, foi o próximo fato que colocou o Estado na posição de assegurar a inclusão dessa parcela da população via leis de seguridade social.
} 
possibilidades $^{25}$. Isso se expressa na 'competência-competência' como nova atribuição do Estado moderno. O sistema da política é considerado o endereço adequado e competente para problemas não solucionados. No entanto, a demanda por uma atuação proativa do Estado entra em choque com a sua capacidade de condução política, haja vista as restrições que lhe impõe a globalização ${ }^{26}$.

A assunção das obrigações atribuídas ao Estado traduz-se numa ampliação dos direitos dos cidadãos, e isso faz com que o conceito de cidadania estenda-se cada vez mais em direção a uma descrição geral da condição de cidadão. A sua ausência é identificada a partir da não efetividade dos direitos constitucionais. Diferentemente de outras constituições, as leis na Constituição brasileira não possuem mecanismo auto-aplicável.

Essas tendências já estavam presentes na obra de Marshall (1967) e na sua compreensão das características constitutivas da cidadania moderna $^{27}$ : universalidade (direitos universais para categorias sociais formalmente definidas), territorialidade (o território determina a abrangência dos direitos atribuídos), individualidade (os direitos referem-se a vínculos diretos entre indivíduos e o Estado) e a concepção estatal-nacional (compreende um vínculo constitutivo entre cidadania e edificação do Estado-nação). Na sua análise, Marshall (1967) enfatiza o caráter evolutivo da cidadania. Os direitos civis transformam-se em direitos políticos, e, após a Primeira Guerra Mundial, os direitos sociais somam-se às atribuições da cidadania.

Numa lógica contratual, a Constituição descreve as condições de transferência de liberdades individuais para o Estado enquanto organização coletiva. Historicamente essas condições modificaram-se no sentido de ampliação das obrigações do Estado em relação aos seus cidadãos. No que concerne às obrigações do Estado, podem-se distinguir pelo menos quatro fases: garantia da vida e da propriedade dos cidadãos, garantia da participação nas decisões com obrigatoriedade coletiva, garantia de condições básicas de bem-estar social dos cidadãos e garantia de condições ambientais que possibilitem a manutenção da vida.

Vasak (1977) introduziu a classificação dos direitos humanos em três gerações:

\footnotetext{
${ }^{25}$ A globalização modifica o contexto da atuação do Estado nacional, deslocando esse balanço em direção à economia. O problema dos sistemas políticos modernos é a falta de poder; assim sendo, eles tornam-se objeto de interesses míopes e egoístas (WILLKE, 2006).

${ }^{26}$ A globalização transformou o Estado em semi-soberano, e sua atuação ou omissão em questões de inclusão/exclusão ou cumprimento/não-comprimento de direitos humanos fica exposta ao mundo por meio da mídia.

${ }^{27}$ A globalização e os processos de exclusão social a ela atribuídos fazem surgir nos anos 90 uma onda de trabalhos sobre cidadania que não podemos discutir aqui. Eles introduzem novas questões, como a relação entre participação e cidadania, entre cidadania e referência territorial, entre cidadania e capacidade de exercer a cidadania (citizenship capacity), entre cidadania e diversidade/pluralismo.
} 
a) direitos de primeira geração, que visam à liberdade e à participação na vida política;

b) direitos de segunda geração: direitos criados para garantir as condições mínimas de igualdade entre os cidadãos (direito de emprego, de moradia, de saúde, de seguridade social etc.);

c) direitos de terceira geração, direitos que ultrapassam a dimensão política e social e que se referem a idéias que ultrapassam o âmbito restrito do Estado-nação (direito à comunicação, a um ambiente saudável, ao desenvolvimento, à igualdade intergeracional etc).

\section{Exclusão/inclusão em uma região de modernidade periférica: um estudo no Estado do Pará}

Com base nessa reflexão teórica introdutória, apresentaremos na segunda parte do trabalho dados empíricos sobre um caso concreto de inclusão/exclusão em uma região de modernidade periférica. Escolhemos como objeto de estudo os direitos de pessoas portadoras de deficiência, e interessa-nos identificar o grau de exclusão/inclusão social desse grupo e a forma da atuação do Estado em relação a esse segmento .

A escolha do tema - pessoas portadoras de deficiência - não foi casual e obedece a determinados critérios que serão rapidamente enunciados. Entendemos a deficiência não somente como uma característica individual, mas sobretudo como um fenômeno social que pode atingir todos, por meio de acidente, de doença ou de restrições impostas pela idade. A maneira como se manifesta a deficiência ou como ela se perpetua devido à falta ou à ineficiência de medidas de recuperação e reabilitação está diretamente ligada ao grau da organização social e do desenvolvimento econômico da sociedade regional. O trato que a sociedade dispensa às pessoas com deficiência mostra a sua capacidade de lidar e de conviver com aqueles que são diferentes. Por último, tal escolha remete diretamente à discussão teórica anterior. Mostramos que a exclusão social é definida como uma perda do endereço social e que os excluídos são reduzidos a sua corporalidade. A satisfação das necessidades básicas do corpo torna-se objetivo principal, e o corpo transforma-se em instrumento de inclusão social, já que uma sociedade que venera o corpo abre essas possibilidades. Aparentemente portadores de deficiência são excluídos desse mecanismo individual de inclusão e necessitam de outras formas de inclusão. Isso faz deles um espelho interessante, que mostra como o poder público enfrenta e resolve problemas de exclusão social.

\section{O desafio: a inclusão de pessoas portadoras de deficiência}

A Convenção sobre os Direitos das Pessoas com Deficiência, aprovada pela Assembléia Geral das Nações Unidas em dezembro de

\footnotetext{
${ }^{28}$ Os dados empíricos que serão apresentados foram colhidos durante a pesquisa para a elaboração de um diagnóstico sobre a situação dos direitos humanos no Estado do Pará (LIMA et al., 2007).
} 
2006, no seu artigo $1 .^{\circ}$, define pessoas com deficiência ${ }^{29}$ como aquelas que têm impedimentos de natureza física, intelectual ou sensorial, os quais, em interação com diversas barreiras, podem dificultar ou impedir sua participação plena e efetiva na sociedade, juntamente com as demais pessoas.

Essa Convenção obriga os Estados signatários a promover a plena realização de todos os direitos humanos e de todas as liberdades fundamentais para todas as pessoas com deficiências, sem qualquer discriminação por causa da sua deficiência. Essa obrigação traduz-se, sobretudo, em políticas públicas que visem garantir os direitos reconhecidos na Convenção e em medidas de superação das discriminações existentes. Ademais, os Estados assumem o compromisso de fomentar a pesquisa e o desenvolvimento de produtos, serviços, equipamentos e instalações que atendem as necessidades especiais de pessoas com deficiências. A institucionalização das políticas públicas será supervisionada por um Comitê sobre os Direitos das Pessoas com Deficiência.

No mesmo documento, considera-se como discriminação qualquer diferenciação, exclusão ou restrição baseada em deficiência, com o propósito ou o efeito de impedir ou impossibilitar o reconhecimento, o desfrute ou o exercício, em igualdade de oportunidades com as demais pessoas, de todos os direitos humanos e de todas as liberdades fundamentais nas esferas política, econômica, social, cultural, civil ou em qualquer outra.

Ainda, com relação à definição das deficiências, a Associação Americana de Deficiência Mental identifica a deficiência mental como um funcionamento intelectual inferior ao da média das pessoas, que representa dificuldades de adaptação ao entorno (Manual Diagnóstico e Estatístico de Transtornos Mentais). Essas dificuldades de adaptação podem estar ligadas a comunicação, cuidados pessoais, competências domésticas, habilidades sociais, utilização de recursos comunitários, autonomia, saúde e segurança, aptidões escolares, lazer e trabalho. Na maioria das vezes, a deficiência é considerada um transtorno de desenvolvimento ${ }_{30}$ e o início da deficiência mental deve acontecer antes dos dezoito anos . Há inúmeras causas e fatores de risco para a instalação

\footnotetext{
29 Na literatura especializada, trabalha-se com pelo menos dois modelos teóricos para definir deficiência: o modelo médico e o modelo social. De acordo com o modelo social, deficiência, afirmam Medeiros e Diniz, em A nova maneira de se entender a deficiência e o envelhecimento, "é considerada uma experiência da interação entre as características corporais do indivíduo e as condições da sociedade em que ele vive, isto é, da combinação de limitações impostas pelo corpo com algum tipo de perda ou redução da funcionalidade (lesão) a uma organização social pouco sensível à diversidade corporal" (DINIZ; MEDEIROS, 2004, p. 8). Essa posição é contrária à do modelo médico, segundo o qual a pessoa deficiente é alguém com algum tipo de inadequação para a sociedade. Nesse sentido, o modelo social inverte o argumento e identifica a deficiência na inadequação da sociedade para incluir todos, sem exceção.

${ }^{30}$ Há várias formas de classificar a deficiência mental: a) com base na intensidade do apoio necessário, b) com base na capacidade funcional do deficiente e c) conforme a gravidade da deficiência (Organização Mundial da Saúde (OMS) - CID 10). Há uma tendência para abandonar as classificações baseadas em comportamentos esperadas por faixa etária e substituí-las pela idéia de uma contextualização social, em que o grau de comprometimento da deficiência mental depende também da história de vida, do apoio familiar e das oportunidades vivenciadas.
} 
da deficiência mental: causas pré-natais, como desnutrição materna, má assistência à gestante, doenças infecciosas, tóxicos, fatores genéticos; causas perinatais (do parto até o 30. ${ }^{\circ}$ dia de vida), como má assistência, oxigenação cerebral insuficiente, prematuridade e baixo peso; fatores pós-natais (até a adolescência), como desnutrição, desidratação, carência de estimulação, infecções, intoxicações, acidentes e infestações.

A Organização das Nações Unidas (ONU) calcula ${ }^{31}$ que, nos países em desenvolvimento, a incidência de jovens de 18 anos e menos com retardo mental grave fica em torno de 4,6\%, enquanto nos países desenvolvidos o valor oscila entre $0,5 \%$ e 2,5\%.

\subsection{O universo dos portadores de deficiência no Estado do Pará}

No que se refere aos dados sobre o número de pessoas com deficiência no Estado do Pará, não há consenso. Conforme dados do Instituto Brasileiro de Geografia e Estatística (IBGE) (Censo 2000), 15,3\% da população residente no Estado declaram ser portadores de pelo menos uma deficiência ${ }^{32}, 71 \%$ vivem na zona urbana e 29\% na zona rural. Esses dados podem indicar que o ambiente urbano é mais propício para adquirir deficiências ou que as pessoas com deficiência migram para os centros urbanos à procura de assistência. Importa registrar que as pessoas com deficiência mental permanente perfazem um universo de 86.719 indivíduos com uma distribuição nas áreas rurais e urbanas muito parecida com o padrão da população em geral. Os dados censitários para o Brasil indicam porcentagens mais elevadas tanto para o universo das pessoas com pelo menos uma deficiência $(18,8 \%)$ quanto para as pessoas com deficiência mental permanente.

Com base na atualização da população residente do Estado ${ }^{33}$, podemos estimar que atualmente (setembro de 2007) vivem cerca de 1.100.000 de pessoas portadoras de deficiência no Estado do Pará, sendo 100.000 portadoras de deficiências mentais permanentes.

Os dados do IBGE baseiam-se na declaração do entrevistado e podem ser contrastados com os dados da Organização Mundial de Saúde (OMS) e com os resultados de uma pesquisa feita pela Associação Fluminense de Reabilitação (AFR) em Belém no ano de 2002.

A OMS trabalha com as seguintes taxas de incidência de deficientes na população: $5 \%$ de deficientes mentais, $2 \%$ de deficientes

\footnotetext{
${ }^{31}$ No cálculo de prevalência de um transtorno mental dentro de um grupo social, é necessário definir o tipo de prevalência: prevalência de ponto (o transtorno é presente em certa fase da vida), prevalência de período (o transtorno pode estar presente a qualquer tempo durante certo período) e prevalência vitalícia (o transtorno é presente durante toda a vida).

${ }^{32}$ Atendendo as reivindicações da Coordenadoria Nacional para a Integração de Pessoas com Deficiências (CORDE), o IBGE ampliou no último censo o seu conceito de deficiências, incluindo "a percepção que as pessoas pesquisadas têm em relação às alterações provocadas pela deficiência na sua capacidade de realização, comportamento e participação social" (BRASIL, 2004, p. 11). Os quadros abaixo mostram os resultados, evidenciando que a deficiência visual foi a mais citada.

${ }^{33}$ IBGE (2006). Estimativas das populações residentes, em 1. ${ }^{\circ}$ de julho de 2006.
} 
físicos, 1,5\% de deficientes auditivos, 0,5\% de deficientes visuais e 1\% de portadores de deficiências múltiplas. No caso do Estado do Pará, essas porcentagens representam um total de cerca 714.000 pessoas ${ }^{34}$.

No que diz respeito às pesquisas realizadas sobre prevalência de deficiências, incapacidades e desvantagens no Brasil, a AFR pesquisou em 2002 uma amostra de 1001 domicílios usando uma metodologiapadrão da Organização Pan-Americana de Saúde. De acordo com os levantamentos socioeconômicos, as pessoas com indicativo de deficiência foram submetidas a um exame clínico por um profissional da saúde para diagnosticar o tipo de deficiência ou incapacidade. Considerando-se a população atual da cidade de Belém ${ }^{35}$, temos um universo de 300.000 pessoas com incidência de deficiência ou incapacidade.

\subsection{Deficiência e direitos humanos}

Para discutir o tema das deficiências no contexto dos direitos humanos, comparamos a realidade vivida pelos sujeitos no Estado do Pará com os direitos assegurados para a sua categoria, segundo as respectivas convenções internacionais que definem os padrões aceitos no conjunto dos Estados democráticos. No caso de pessoas com deficiência, isso nos remete à Convenção sobre os Direitos das Pessoas com Deficiência, elaborada no âmbito das Nações Unidas, que, embora ainda não esteja ratificada pelo Brasil, define hoje o padrão desejável das garantias que o poder público deve assegurar aos seus cidadãos com deficiências. Essas garantias são ${ }^{36}$ :

a) igualdade e não discriminação;

b) conscientização;

c) acessibilidade;

d) direito à vida;

e) situações de risco e emergências humanitárias;

f) reconhecimento igual perante a lei;

g) acesso à justiça;

h) liberdade e segurança da pessoa;

i) prevenção contra a exploração, a violência e o abuso;

j) vida independente e inclusão na comunidade;

l) mobilidade pessoal;

m) liberdade de expressão e de opinião e acesso à informação;

n) respeito à privacidade, pelo lar e pela família;

\footnotetext{
${ }^{34}$ Com base nessas informações, podemos construir a seguinte estimativa atual para o Estado do Pará: 357.253 pessoas com deficiência mental, 142.901 pessoas com deficiência física, 107.176 pessoas com deficiência auditiva, 35.725 pessoas com deficiência visual e 71.451 pessoas com deficiências múltiplas.

${ }^{35}$ População do município de Belém: 1,4 milhões.

${ }^{36}$ Colocarei as garantias nesse nível de detalhamento para mostrar o grau de amplitude e para facilitar a avaliação da atuação do poder pública perante o desafio colocado.
} 
o) educação;

p) saúde;

q) habilitação e reabilitação;

r) trabalho e emprego;

s) participação na vida política e pública;

t) participação na vida cultural e em recreação, lazer e esporte.

\section{Grau de atendimento e violação dos direitos de pessoas com deficiência}

Com base na apresentação acima do arcabouço normativo construído pela Convenção e do grupo que deve ser protegido, vamos a seguir avaliar a efetividade dos direitos enunciados .

No que concerne ao direito de igualdade e não discriminação, utilizamos dois indicadores na pesquisa: a existência e o funcionamento de conselhos de usuários, de um lado, e a relação entre existência de transtorno mental e empobrecimento, de outro.

Quanto ao primeiro indicador, constatamos que o órgão máximo de representação das pessoas com deficiência é o Conselho Nacional de Direitos da Pessoa Portadora de Deficiência. Esse órgão está ligado à Secretaria Especial dos Direitos Humanos. Não há conselho no âmbito do Estado do Pará, nem no âmbito dos municípios.

Quanto ao segundo indicador, observamos que a comparação da parcela da população economicamente ativa que apresenta deficiência mental com os dados gerais mostra que o grupo em foco possui algumas características específicas em relação à população geral. De um lado, o número dos que possuem trabalho remunerado na semana de referência foi bem inferior no grupo das pessoas com deficiência; de outro lado, o número dos que recebem rendimentos de pagamentos de transferência, como aposentadoria e pensão, é maior. A média dos rendimentos no grupo geral é 42\% superior à da população com deficiência mental.

No que diz respeito ao direito de mobilidade pessoal, trabalhamos com um indicador concernente às formas de adaptações existentes para aumentar o grau de mobilidade das pessoas com deficiência.

A primeira conferência estadual dos direitos da pessoa com deficiência, que aconteceu em 2006 em Belém, cujo tema foi "Acessibilidade: você também tem compromisso", elaborou uma extensa lista de reivindicações, visando garantir a acessibilidade nas suas diversas faces. A legislação municipal garante às pessoas com deficiência o direito de passe livre para uso nos meios de transporte público. No entanto, a Companhia de Trânsito de Belém (CTBEL) vincula a concessão do passe

\footnotetext{
${ }^{37}$ A escolha dos indicadores para a verificação foi feita de forma pragmática, pensando na sua sustentabilidade, isto é, na sua aptidão futura para acompanhar e monitorar a política.
} 
a uma avaliação da existência da deficiência pela própria Companhia, sem possuir capacidade médica para fazer tal avaliação.

\begin{tabular}{|c|c|c|}
\hline & \begin{tabular}{|c|} 
Fortador es de deficiên cia \\
mental perm an ente com mais \\
de 10 anos de idade
\end{tabular} & $\begin{array}{l}\text { Populaçāo r esidente do Estado } \\
\text { do Pará com mais de } 10 \text { anos } \\
\text { de idade }\end{array}$ \\
\hline Fossui tr abalho remunerado (V0439) & $16,50 \%$ & $36,20 \%$ \\
\hline $\begin{array}{l}\text { Frin cipal respon sável pela } \\
\text { m anuten gào da família (V0402) }\end{array}$ & $26,10 \%$ & $29,40 \%$ \\
\hline $\begin{array}{l}\text { Tem ren dim ento oriun do de ren da } \\
\text { mínima, bolsa escola, seguro } \\
\text { desempr ego (V0603) }\end{array}$ & $0.70 \%$ & $0.50 \%$ \\
\hline $\begin{array}{l}\text { Tem rendimento oriun do de } \\
\text { aposentadoria ou pensāo (V4573) }\end{array}$ & $34.70 \%$ & $9,20 \%$ \\
\hline Era aposentado (V0456) & $27,20 \%$ & $6,90 \%$ \\
\hline Nàotem rendimentos (V4614) & $45,40 \%$ & $49,40 \%$ \\
\hline $\begin{array}{l}\text { Média dos ren dimentos em salários } \\
\text { mínimos (V4615) }\end{array}$ & 1.1 & 1.5 \\
\hline
\end{tabular}

Quadro 1: Comparação da população economicamente ativa (PEA)no Estado do Pará: portadores de deficiência mental e população total (2000). Fonte: IBGE. Censo 2000. Amostragem. Cálculo próprio.

No que se refere ao direito da liberdade de expressão e de opinião e acesso à informação, escolhemos como indicador a existência de informações em mídia especial para deficientes em órgãos públicos e em bibliotecas públicas. Registramos que não existem nos órgãos públicos materiais informativos em mídia especial.

Para avaliar o direito à educação, adotamos dois indicadores: a existência do ensino fundamental gratuito e a não exclusão de pessoas com deficiência do sistema educacional, de um lado, e a existência de professores habilitados (inclusive com deficiências) atuando no ensino de pessoas portadoras de deficiências, de outro.

A avaliação do primeiro indicador indica que a metade dos estabelecimentos destinados exclusivamente à educação especial no Estado do Pará é de caráter privado. No setor público, prevalecem as escolas que integram os alunos com necessidades especiais em salas de aula comum, na sua maioria sem sala com recursos especiais. No conjunto dos estabelecimentos de ensino do Estado, as escolas com classes de integração ainda são uma minoria. Somente 9\% de todos os estabelecimentos municipais de educação oferecem classes de integração; a média nacional é $23 \%$. Dos estabelecimentos sob a administração estadual, 18\% possuem classes de integração, o que fica novamente abaixo da média nacional, que é 36\%.

Conforme dados do Censo Escolar de 2005, o Brasil tem 640.317 alunos portadores de necessidades especiais matriculados nas escolas. Desse contingente, quase a metade está matriculada em escolas exclusivamente destinadas a pessoas portadoras de necessidades especiais. No Pará, 16.842 alunos com necessidades especiais são 
matriculados, e 31,9\% desse total estudam em escolas especializadas. O grupo dos alunos com deficiência mental abrange 34,6\% do total dos alunos portadores de necessidades especiais matriculados no Estado.

No Brasil, quase $80 \%$ dos alunos matriculados em escolas especializadas estudam em estabelecimentos particulares. Na região Norte e no Estado do Pará, esse percentual é inferior, visto que as escolas especializadas estaduais absorvem uma gama significativa desse alunado, diferente da tendência no âmbito nacional.

A maioria dos alunos com deficiência visual, deficiência mental, deficiência múltipla, síndrome de Down e autismo estuda em escolas especializadas. Um terço das vagas nesse tipo de estabelecimento é ocupado por alunos com deficiência mental.

Nas classes comuns - tipo integração - que não possuem sala de recursos, encontra-se a maior parte dos alunos com baixa visão e deficiência física. A classe comum - tipo integração - com sala de recursos concentra a quase totalidade dos alunos superdotados.

Existe ainda uma grande discrepância entre a área urbana e a área rural no que tange à oferta de oportunidades educacionais para portadores de necessidades especiais. Uma análise das matrículas demonstra que os estabelecimentos especializados ou as escolas regulares com classes especiais ainda são muito raros na área rural. A principal oferta na área rural são as salas comuns (tipo integração), mas sem salas com recursos adequados.

Na análise do segundo indicador, relativo à atuação de professores habilitados para a formação de deficientes, identificamos que, a partir do início de 2007, o Centro de Atendimento Educacional Especializado da Secretaria Municipal de Educação de Belém (SEMEC) assume a responsabilidade de assessorar e treinar os professores para o seu trabalho com alunos portadores de deficiência. Esse atendimento também inclui ajuda aos familiares. A sede recém-inaugurada está ainda se estruturando, mesmo que as atividades sejam desenvolvidas desde 1997 por uma Unidade ou Coordenadoria da SEMEC.

Quanto ao direito à conscientização da sociedade sobre as condições dos deficientes, definimos como indicador a existência e as formas de campanhas de conscientização. No entanto, constatamos que não existem campanhas públicas de conscientização promovidas pelo poder público.

Com relação ao direito à acessibilidade em igualdade de oportunidades ao meio físico, ao transporte, à informação e à comunicação, escolhemos como indicador a porcentagem de prédios públicos com acesso adaptado para o público em geral e para funcionários. Registramos que não existem dados organizados informando o número de prédios públicos ainda sem acesso adaptado.

Para verificar o direito do acesso à justiça, elegemos como indicadores a população carcerária com deficiências e a existência e a qualidade de programas de treinamento para agentes do sistema 
prisional ou sistema de repressão (polícias militar, civil e federal). Conforme informação da Superintendência do Sistema Prisional (SUSIPE), na população carcerária, há 16 pessoas portadoras de deficiência física, seja por trauma, seja por má formação (dado de maio de 2007). Também consta desse universo um contingente de 137 pessoas identificadas como portadoras de doença mental, distribuídas em 15 casas prisionais. Foi informado que não existem programas de treinamento específico para agentes do sistema prisional para lidar com pessoas com deficiência.

No quesito do direito à liberdade e à segurança da pessoa, selecionamos como indicador as adaptações feitas nas edificações do sistema prisional e nas delegacias. Registramos que não há adaptações para atendimento dos portadores de necessidades especiais nas edificações do sistema prisional, nem nas delegacias.

Com relação ao direito de prevenção contra a exploração, a violência e o abuso, utilizamos como indicador a existência e a qualidade de programas de monitoramento independentes nas instalações e intervenções direcionadas a pessoas com deficiência. Constatamos que não existem sistemas de monitoramento independente nas instalações do sistema prisional.

No que se refere ao direito aos serviços de saúde específicos para pessoas com deficiências, tanto em áreas rurais como urbanas, encontramos o seguinte quadro: a partir da reforma psiquiátrica, os Centros de Atenção Psicossocial (CAPS) assumem um papel estratégico na articulação da rede de atenção à saúde mental ${ }^{38}$. Os CAPS distinguem-se pelo tamanho e pela especificidade da sua demanda. Há o CAPi, voltado para a infância e a adolescência, e há o CAPSad, destinado ao atendimento de usuários de drogas e álcool . Apesar da expansão da rede de atendimento, o grau de cobertura no Estado ainda se encontra abaixo do desejável: 0,27 CAPS/100.000 habitantes, e o recomendável é 0,5 CAPS/100.000 habitantes

No que tange ao direito de habilitação e reabilitação, consideramos dados referentes ao município de Belém e ao Estado.

\footnotetext{
${ }^{38}$ Os CAPS surgem primeiramente em São Paulo (1986). Integrantes do Sistema Único de Saúde (SUS), seu funcionamento é regulamentado pela Portaria n. ${ }^{\circ}$ 336/GM, de 19 de fevereiro de 2002. As principais atribuições dos CAPS são: atendimento em regime de atenção diária, gerenciamento dos projetos terapêuticos, promoção da inserção social dos usuários e funcionamento como porta de entrada da rede de assistência social em saúde mental. Os atendimentos podem ser: intensivo, com atendimento diário para pessoas em crise, ou para pessoas que precisam de atenção continua; semi-intensivos, com até 12 atendimentos por mês, inclusive com atendimentos domiciliares; não intensivos, com até três atendimentos por mês, inclusive com atendimentos domiciliares.

${ }^{39}$ No Estado do Pará, existem 26 CAPS, 3 CAPSad e 1 CAPSI (Fonte: Ministério da Saúde. Disponível em: <http://www.ccs.saude.gov.br/saude_mental/hospitais.html>. Acesso em: 5 jul. 2007).

${ }^{40}$ Fonte: Ministério de Saúde. Coordenação Geral de Saúde Mental. Relatório de Gestão 20032006. Brasília, DF, 2007, p. 15. Para fins de cálculo, define-se que o CAPS I dá resposta a 50.000 habitantes, o CAPS II, o CAPSi e o CAPSad, a 100.000 habitantes e os CAPS III, a 150.000 habitantes.
} 
No município de Belém, os serviços de proteção socioassistencial à pessoa com deficiência são executados por entidades e organizações sociais integrantes da Rede de Proteção Social, coordenada pela Fundação Papa João XXIII (FUNPAPA). Essas organizações dispõem de equipamentos e de pessoal especializado para o desenvolvimento de ações de proteção social e inclusão de pessoas que, além de portadoras de deficiências, encontram-se em situação de vulnerabilidade ou de risco pessoal e social. As entidades da rede realizam atividades terapêuticas, educacionais e sociais, com apoio, informação, orientação e encaminhamento, prevenção de deficiência, diagnóstico, avaliação e reavaliação, estimulação precoce, habilitação e reabilitação, atividades ocupacionais, educacionais e sociais. São 792 metas anuais distribuídas entre as seguintes entidades : Associação de Pais e Amigos dos Excepcionais (APAE), Associação Paraense de Portadores de Deficiência (APPD), Instituto Felipe Smaldone, Fundação Pestalozzi e Serviço de Atendimento Básico em Reabilitação (SABER).

No âmbito do Estado, a Secretaria de Trabalho e Proteção Social (SETEPS) atua por meio de programas de auxílio financeiro aos idoșos e deficientes e a suas famílias, como o programa de Mal de Hansen ${ }_{43}^{42} 0$ Benefício da Prestação Continuada , o Bolsa Família, a Família Paraense Fortalecida, o Programa de Atenção Integral à Família (PAIF) - programa do Governo Federal executado por intermédio dos Centros de Referência de Assistência Social (CRAS) -, o Agente Jovem, o Idade Ativa (que se transformará em PISO).

\section{Considerações finais}

Os resultados da nossa pesquisa mostram que, nas regiões de modernidade periférica, a materialização dos direitos dos portadores de deficiência ainda está longe de um patamar desejável. Existe no sistema político uma discrepância entre o discurso e a capacidade de efetivação dos direitos.

Não há números exatos sobre a quantidade de pessoas com deficiência no Estado do Pará, mas, com base nas fontes encontradas, podemos estimar um número entre 700.000 e 1.100.000. A proteção

\footnotetext{
${ }^{41}$ Fonte: Núcleo Setorial de Planejamento (NUSP), da FUNPAPA (2006).

${ }^{42}$ O Programa Mal de Hansen é desenvolvido pela SETEPS e visa garantir o pagamento de um beneficio no valor de um salário mínimo ao portador da doença, desde que o deficiente se encontre em situação de vulnerabilidade. O benefício é pago desde 2000 por cotas mensais, segundo os processos encaminhados à SETEPS pelas Secretarias Municipais de Saúde. A faixa etária atendida é de 5 a 80 anos, com um ano de moradia no Estado do Pará. Até o momento, o Programa atende a 82 municípios do Estado do Pará.

${ }^{43}$ O Benefício da Prestação Continuada (BPC) é um programa federal efetivado pelo município e coordenado, na habilitação, pelo Estado. O Programa atende aos 143 municípios paraenses. Em 2006 somou 2.749 beneficiários/mês que recebem um auxílio no valor de um salário mínimo vigente no país. São beneficiárias as pessoas idosas (com mais de 65 anos) e os deficientes em situação de vulnerabilidade em famílias com renda mensal de até $1 / 4$ do salário mínimo.
} 
desse contingente segundo um conceito amplo de efetivação de direitos humanos ainda está muito aquém do padrão estabelecido pela Convenção sobre os Direitos das Pessoas com Deficiência.

Não resta dúvida de que a Convenção amplia a visão sobre os direitos dos portadores de deficiência, na medida em que o Estado brasileiro acata e assume para si, no conjunto das suas atribuições e competências, as recomendações e orientações postas nesse documento. Ademais, no contexto internacional, o Brasil apresenta-se como um Estado moderno, cuja legitimidade está fundada na garantia de direitos humanos universais para os seus cidadãos.

Essa Convenção imprime um caráter transversal aos direitos dos portadores de deficiência. A materialização dos direitos demanda a presença do tema em todas as organizações especializadas do sistema político-administrativo ${ }^{44}$. Desse modo, a implementação desses direitos assume o caráter de um evento multissistêmico, em que cada organização incorpora o tema às suas estruturas de comunicação e às suas atribuições. A aceitação de uma atribuição adicional não é algo que se faça automaticamente, já que as organizações conservam a sua autonomia, mesmo fazendo parte da estrutura hierárquica da administração pública. Se essa nova atribuição não for acompanhada de um aumento de recursos humanos e financeiros, podem surgir conflitos sobre a redistribuição do recurso existente no interior da instituição. Nesse contexto, a inércia das organizações ${ }^{45}$ impede uma mudança substantiva.

Podemos afirmar que esse mecanismo ganha traços perversos nos casos em que há transferência de responsabilidades da administração de uma organização para outra organização, sem a transferência de recursos. Como exemplo desse fenômeno, podemos citar a reforma psiquiátrica. Em nome da humanização, retira-se dos hospitais psiquiátricos a responsabilidade pelo cuidado com pessoas portadoras de transtornos mentais, e não se cria uma estrutura institucional capaz de absorver esses usuários, cuja sociabilidade em alguns casos é extremamente restrita. Vale lembrar que toda comunicação requer o processamento do sentido que é socialmente reconhecido como sentido.

Usualmente, enfrenta-se esse mecanismo por meio da diversificação do sistema administrativo, surgindo assim organizações que se legitimam por assumirem a responsabilidade específica dos

\footnotetext{
${ }^{44}$ A mesma lógica se aplica para outros temas transversais como proteção ambiental e igualdade entre os gêneros.

${ }^{45}$ Definimos inércia das organizações pela existência de estruturas que reagem a uma perturbação com a intenção de manter a situação existente.
} 
direitos humanos dos portadores de deficiência. Em uma organização especializada, pode surgir um alto grau de engajamento e expertise. No entanto, faz-se necessária a transferência desse engajamento e dessa expertise para dentro de outras organizações especializadas da administração pública. O fechamento operacional ${ }^{46}$ das organizações restringe muito o êxito dessa intervenção ${ }^{47}$.

Nos países de modernidade plena, a inclusão social dos portadores de deficiência ocorre por intermediação das organizações especializadas no atendimento integral desse grupo. Mais uma vez, constatamos que a sociedade reage aos problemas causados pela diferenciação funcional criando uma esfera especializada em amenizar os efeitos da diferenciação funcional. Essa forma de solucionar o problema oculta as possibilidades de gerar inclusão social por meio do acesso aos processos comunicativos. A institucionalização dos portadores de deficiência faz com que os sistemas funcionais se livrem dos sistemas psíquicos, que têm a sua capacidade de comunicação reduzida, e assim criem obstáculos para a continuidade de comunicação como operação básica do sistema ${ }^{48}$. A continuidade desse novo sistema requer recursos $\operatorname{humanos}_{49}$ e financeiros e um fluxo contínuo de excluídos a serem incluídos ${ }^{49}$.

Já em regiões de modernidade periférica, a inclusão por via da instituição caracteriza-se mais pela omissão ou pela incompetência do que pelo excesso, e as tentativas para facilitar aos portadores de

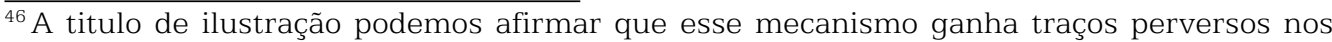
casos em que há uma transferência de responsabilidades da administração de uma organização para outra organização sem a transferência de recursos. Como exemplo desse fenômeno podemos citar a reforma psiquiátrica. Em nome da humanização se retira dos hospitais psiquiátricos a responsabilidade pelo cuidado com pessoas portadoras de transtornos mentais, e não se cria uma estrutura institucional capaz de absorver esses usuários com uma sociabilidade em alguns casos extremamente restrita. Vale lembrar que toda comunicação requer processamento de sentido que é socialmente reconhecido como sentido.

${ }^{47}$ Por fechamento operacional entendemos que o sistema social somente pode-se reproduzir a partir dos seus elementos usando as suas próprias operações. Isso significa que os sistemas sociais são 'imunes' à intervenção externa. A intervenção se manifesta somente como uma perturbação no meio do sistema e o seu processamento será feito dentro das estruturas do sistema. Desse modo, não há como guiar um sistema, pois ele sempre se autoconduz.

${ }^{48}$ A organização tem a sua atuação limitada por duas lógicas antagônicas. De um lado, ela depende na execução das políticas da 'colaboração' de outras organizações do sistema político-administrativo, e, essa colaboração será concedida somente se for do interesse da organização solicitada. De outro lado, o sucesso da sua atuação, expresso no alto grau de engajamento em torno do tema de direitos dos portadores de deficiência nas diferentes instâncias do sistema administrativo, colocaria em risco a existência da organização e ela se tornaria desnecessária já que perdeu a sua função.

${ }^{49}$ Esse ponto está aprofundado em alguns trabalhos de Peter Fuchs, veja por exemplo Fuchs (2002).

${ }^{50}$ A integração dos portadores de deficiência em organizações específicas é ao mesmo tempo uma redução das liberdades dos indivíduos, que são obrigados agora freqüentar instituições especializadas. De que maneira essa inclusão forçada gera conflitos dentro do grupo de portadores seria um estudo interessante.
} 
deficiências a participação no processo comunicativo são quase inexistentes.

Independentemente das privações dos direitos básicos da cidadania, vivenciadas pela maioria dos cidadãos, a situação dos portadores de deficiência diferencia-se pelo fato de o Estado não ter assumido na prática esse grupo como um alvo prioritário da sua política, com exceção de algumas áreas específicas, como a educação, em que há um esforço para assegurar a oferta educacional, pelo menos na área urbana.

Desse modo, a exclusão social das pessoas com deficiência manifesta-se de duas formas ${ }^{50}$ : 1) pela falta de meios físicos que impedem o acesso a determinados serviços e bens públicos, à informação, à recuperação ou à reabilitação; 2) pela tentativa velada do poder público de ofuscar a existência das pessoas portadoras de deficiência na vida social, em função de ausência de conscientização da população sobre as especificidades e necessidades dos deficientes. Ainda importa salientar a omissão dos partidos políticos, que não inserem essa questão nas suas agendas políticas.

Para efetivação da política nacional dos direitos dos portadores de deficiência, torna-se imprescindível 1) a transformação da exclusão social em inclusão social de grande parte da população dos portadores de deficiência (privada da participação em um ou mais sistemas funcionais) por meio da construção de endereços sociais para os sistemas psíquicos reduzidos a sua corporalidade e 2) a criação de condições que possibilitem aos portadores de deficiência a participação nos eventos comunicativos dos sistemas funcionais.

Diante do exposto, fica evidente que a deficiência é vista, não como um problema de responsabilidade social, mas como uma característica específica do indivíduo. Esse olhar não leva em consideração o fato de a deficiência estar vinculada às condições materiais objetivas da sociedade, e qualquer indivíduo pode vir a transformar-se em uma pessoa portadora de deficiência, seja em função de um acidente, seja em função de doença ou do processo de envelhecimento.

Apesar das mudanças em curso, o poder público ainda observa a deficiência como uma característica do indivíduo que possui um corpo com uma disfunção ou imperfeição. Sendo assim, o corpo torna-se o instrumento da inclusão social, agora não pela sua beleza ou pela sua habilidade extraordinária, mas em função do seu defeito e da sua inabilidade. 


\section{REFERÊNCIAS}

BRASIL. Ministério da Justiça. Coordenadoria Nacional para Integração da Pessoa Portadora de Deficiência e Associação Fluminense de Reabilitação. Relatório sobre a prevalência de deficiências, incapacidades e desvantagens: sistematização dos estudos realizados em 21 cidades brasileiras, com metodologia de entrevistas domiciliares da Organização Pan-Americana de Saúde. Niterói, 2004.

DINIZ, D.; MEDEIROS, M. A nova maneira de se entender a deficiência e o envelhecimento. Brasília, DF: IPEA, 2004 (Texto para discussão 1040).

FUCHS, P. Das seltsame Problem der Weltgesellschaft. Opladen: Westdeutscher Verlag, 1997a.

FUCHS, P. Adressabilität als Grundbegriff der soziologischen Systemtheorie. Soziale Systeme, v. 3, n. 1, p. 57-79, 1997b.

FUCHS, P. Behinderung und Soziale Systeme. Anmerkungen zu einem schier unlösbaren Problem. Das gepfefferte Ferkel. Online-Journal für systemisches Denken und Handeln. 2002. Disponível em: <http:// www.ibs-networld.de/ferkel>. Acesso em: 10 set. 2007.

HALFMANN, J. Der moderne Nationalstaat als Lösung und Problem der Inklusion in das polítische System. In: HELLMANN, K. W.; SCHMALZBRUNS, R. (Hrsg). Theorie der Politik: Niklas Luhmanns politische Soziologie. Frankfurt a.M.: Suhrkamp, 2002. p. 261-286.

LIMA, R. et al. Diagnóstico dos direitos humanos no Estado do Pará. Belém: UFPA, 2007. Relatório de pesquisa.

LUHMANN, N. Einführende Bemerkungen zu einer Theorie symbolisch generalisierter Kommunikationsmedien. In: LUHMANN, $\mathrm{N}$. Soziologische Aufklärung Band 2: Aufsätze zur Theorie der Gesellschaft. Opladen: Westdeutscher Verlag, p. 170-192, 1975a.

LUHMANN, N. Die Weltgesellschaft. In: LUHMANN, N. Soziologische Aufklärung Band 2: Aufsätze zur Theorie der Gesellschaft. Opladen: Westdeutscher Verlag, p. 72-102, 1975 b.

LUHMANN, N. Kausalität im Süden. Soziale Systeme, v. 1, n. 1, p. 728, 1995. 
LUHMANN, N. Protest: Systemtheorie und soziale Bewegungen. Frankfurt a. M.: Suhrkamp, 1996.

LUHMANN, N. Die Gesellschaft der Gesellschaft. Frankfurt a. M.: Suhrkamp, 1997.

MARSHALL, T. H. Cidadania, classe social e status. Rio de Janeiro: Zahar Editora, 1967.

MATHIS, A. A política do desenvolvimento regional sob a perspectiva da teoria dos sistemas. In. ALTVATER, E. et al. Terra incógnita: Reflexões sobre globalização e desenvolvimento. Belém: UFPA, 1999. p. 249-290.

MATHIS, A. Reflexões sobre a reforma do Estado na Amazônia. In. COELHO, M. C. N. et al. (Org.). Estado e políticas públicas na Amazônia. Belém: CEJUP; UFPA, 2001. p. 121-136.

NASSEHI, A. Politik des Staates oder Politik der Gesellschaft? Kollektivitär als Problemformel des Politischen. In: HELLMANN, K. W.; SCHMALZ-BRUNS, R. (Hrsg). Theorie der Politik: Niklas Luhmanns politische Soziologie. Frankfurt a.M.: Suhrkamp, 2002. p. 38-59.

NEVES, M. Verfassung und Positivität des Rechts in der peripheren Moderne. Eine theoretische Betrachtung und eine Interpretation des Falls Brasiliens. Berlin, 1992.

NEVES, M. The symbolic force of human rights. Philosophy \& Social Criticism, v. 33, n. 4, p. 411-444, 2007. DOI: 10.1177/ 0191453707077014.

SOUZA, J. A modernização seletiva: uma reinterpretação do dilema brasileiro. Brasília, DF: Ed. UNB, 2000.

STICHWEH, R. Inlusion/Exklusion, funktionale Differenzierung und die Theorie der Weltgesellschaft. Soziale Systeme, v. 3, n. 1, p. 123-136, 1997.

VASAK, K. Human Rights: A Thirty-Year Struggle: the Sustained Efforts to give Force of law to the Universal Declaration of Human Rights, UNESCO Courier 30:11. Paris: United Nations Educational, Scientific, and Cultural Organization, 1977.

WILLKE, H. Global Governance. Bielefeld: transcript Verlag, 2006. 
